\title{
Analysis on Geriatric Social Work Service Absence in Civilian-run Retirement Organizations -Taking the Service Status of Civilian-run Retirement Organizations in Tianjing City as an Example
}

\author{
Guofeng Bian
}

\author{
Tianjin Vocational Institute, Tianjin, 300410, China
}

\begin{abstract}
Keywords: Retirement Organizations, Civilian-run, Geriatric Social Work
\end{abstract}
\begin{abstract}
With civilian-run retirement organizations becoming more and more important in solving the organization retirement of current urban aged population, the service quality of civilian-run retirement organizations also becomes people's focus of attention. This paper points out that problems of geriatric social work function absence universally exist in civilian-run retirement organization service. The civilian-run retirement organizations can't effectively provide service in aspects like old people's “admission evaluation" and "living quality intervention”, nursing workers' "working pressure and negative emotion guidance". As a result, they are unable to offer personal, demanded and effective nursing, causing low satisfaction degree of old people's living quality and frequent loss of nursing workers. This paper holds that one reason for this universal problem of civilian-run retirement organizations is nursing worker shortage. Investors and managers temporarily regard body nursing effects as sole benefit pursuit. The second reason is that investors and managers both start from cost saving and cut down the cost of hiring professional social workers. The third reason is that managers' "illiterate” understanding of social working knowledge and idea causes the function absence of geriatric social work. The author thinks that the function absence of geriatric social work will become the critical factor of restricting the service quality promotion of civilian-run retirement organizations.
\end{abstract}

Aging problem has become a hot topic discussed by people in current society. Aging of population in Tianjing City ranks the third among big cities in China, following Shanghai and Beijing. According to the sixth nationwide census data in 2010, the permanent residences in Tianjing City have reached 12938200 . The total population of census register in Tianjing City is 9848500 with 1764000 aged people over 60 years old which takes up 17.91\% of total population. Rapid increasing of aged population in Tianjing City has caused strong requirement for pension service. With the increasing of governmental input and constantly carrying out of old-benefited policies, the social force civilian-run retirement organization grows rapidly. After several years of development, there are more than 300 all kinds of retirement organizations in Tianjing City with 278 civilian-run retirement organizations until June 2013.

Under the situation that beds in state-run retirement organizations are limited, the development of civilian-run retirement organizations relives government's pressure and solve problems for the common people.

\section{Main functions of geriatric social work in retirement organizations}

Geriatric social work refers to a professional helping service activity which means using professional means and skills to help and improve old people's living environment and living quality under the direction of altruism value. At present, the average level of domestic social work occupation is low, so the main activity range of geriatric social work is in retirement organizations. It plays a vital role in geriatric nursing work in retirement organizations.

1.1 Admission evaluation of old people

Living evaluation concerns contents about the old people which generally contain the following aspects: (1) Basic sociodemographic information: it refers to old people's natural situations and social relationship status like name, gender, date of birth, past occupation, marital status, children status, etc. Grasping the information will make clear old people's supporting system. (2) Physical conditions: how are old people's physical conditions? Do they have difficulties in walking? Do they 
have difficulties in body flexibility? Have they once experienced stroke? How is their level of consciousness? How is their listening ability? What common diseases do they have? What is their health insurance status? The most important problem is old people's attitude toward their own physical conditions. (3) Mental functions: it includes personality, intelligence, memory, and alzheimer disease. Their mental health conditions directly determine how to interact with them in service process and what problems should caregivers pay attention to. (4) Spiritual and emotional status: it contains old people's depressive state, anxiety state, evaluation of self status, sense of self-respect, etc. Old people's emotional conditions when entering the hospitals will directly determine their adaptation speed for retirement organizations. (5) Ability of daily life: whether the old people can manage their own life? Do they need intervention service? What is the degree of intervention service? (6) Economic conditions: what is old people's financial resource? Can they normally afford the expense of living in retirement organizations? Or who should be the one to afford it? In addition, what economic or material assistance can the old people enjoy?

\subsection{Living quality intervention of old people}

Geriatric social workers can reasonably make targeted one-to-one individual service or group service in accordance with old people's admission evaluation and current bad condition evaluation. For example, individual service aims at old people's anxiety problem, depressive problem, aloneness, grief of losing spouse, etc. Group service helps old people deal with problems like companionship, attention shift, sense of belonging, comfortable housing, etc. Life satisfaction is like the index of "happiness" with strong subjectivity. Old people's degree of satisfaction for their retirement organizations depends on their subjective judgment of living conditions. Such kind of judgment is able to be measured. When social work service works, old people's joyful feeling in retirement organizations will be increased, which will greatly increase their dependence on retirement organizations. Taking the second agedness flat in Tianjing as an example, this social work department has existed for more than 10 years. It is one of few retirement organizations with social work service in Tianjing City. Professional social workers in this organization carry out intervention service for the old people such as admission adaptation service, living assistance for the independent old people, psychological guidance for semi- independent old people, companionship for old people of no family. It refers to multiple aspects like self-confidence building, self-confidence maintainance, aloneness adjustment, depressive emotion mitigation, interest group activities, etc. The service makes the old people enjoy physical and mental pleasure and rich life. Through measurement, the old people who have experienced social work service in this organization have generally high life satisfaction.

1.3 Working pressure of nursing workers and negative emotion guidance

The service object of retirement organizations isn't confined to the old people, nursing workers and other workers are also the service object of social workers. Communication with the old people is different from communication with children, because children always bring people hope but the old people must face the irreversible death no matter how good the care is. Nursing workers who nurse the old people for a long time have not only physical load but also "companionship with death”. When negative emotion is accumulated to a certain degree, they may vent to the old people or quit to find other jobs or abuse the old and deliberately ignore them. Social workers' attention of nursing groups and negative emotion guidance will effectively relive nursing workers' pressure and protect their mentality. It is beneficial to improving nursing workers' service quality and maintaining nursing groups' stability.

\section{Service status and dilemma of civilian-run retirement organizations after geriatric social work function absence}

2.1 Lacking professional old people's admission evaluation causes their demands unable to be pointedly fulfilled

In civilian-run retirement organizations, when entering retirement organizations the old people must get through a link named "filing" which means basic information collection of old people's natural status, physical condition, relatives status, economic conditions, etc for sake of 
dealing with their emergency. Without professional geriatric social work service, the incomprehensive "filing" information ignores the old people's living demands. The sole information is at a isolated “zero" junction state and can’t be used scientifically and reasonably in geriatric nursing work. Therefore, the workers don't have a scientific decision of problems like old people's hobbies and interests, character and personality, psychological status, current demands, matters needed to be noticed in nursing, profitable activities for the old people, etc. Their nursing is merely confined to physiological nursing. They can't use the effective information like spiritual needs, emotional state and geriatric functional condition to make comprehensive service programme aiming at the old people's individual needs, ignoring individual characteristics, causing slow adaptation to life in organizations, and aggravating their emotional and physiological obsession.

2.2 No attention is paid to the old people's living quality and intervention causes low degree of satisfaction

The service function standards in Standards of Social Welfare Institution for the Elderly published by Ministry of Civil Affairs explicitly stipulate that social welfare institution for the elderly must provide the old people with four aspects of service namely food, nursing, recovery and mentality. The specific requirement for psychological service is as follows:

"Communicating with the old people for more than 15 minutes everyday, and keeping conversation record; timely grasping the emotional changes of each old people; solving universal problems and extreme personal problems through collective researches; maintaining the old people's self-confident state."

"Usually organizing the old people to conduct essential emotional communication and social interaction; helping the old people build brand new social bond; basically meeting their needs of emotional communication and social interaction; erratically organizing the old people to take part in social activities and make contribution to social development in accordance with their speciality, physical conditions, and social participation willingness."

It can be concluded from the standard contents that the national requirement for geriatric nursing is "systemic and comprehensive nursing". That is to say, retirement organizations should not only offer the old people physical nursing but also psychological care. The carrying out of this social function can't be realized without the participation of social workers.

2.3 Poor management of voluntary service resources causes "well-meaning" harm to the old people

Civilian-run retirement organizations are lack of social work idea and corresponding service functions, so it is universally reflected by the old people that the daily cultural life is dull and the atmosphere in organizations is depressed. In order to improve the atmosphere, managers use the voluntary service resources outside of organizations, accept volunteers' consolation and performance on holidays and festivals without any requirement, and unconditionally welcome teachers and students in universities and colleges to practice for a short term. The voluntary service which seems lively in fact takes the old people as experimental articles. Generally the short-term volunteers come to retirement organizations to offer short-term or time-limited service in order to accomplish their tasks, projects or even the internship of a certain subject. When they come, the organizations are extremely lively. When they leave, they have never been heard ever since and they won't contact the old people. Their passion and interest which have been aroused just now will be greatly damaged. These civilian-run retirement organizations are lack of professional social work idea and occupational values, so they don't have the awareness of checking the quality of volunteer service, standardizing the technology of volunteer service, and forming institutionalized long-term voluntary service plan. It finally causes uneven voluntary service and strong temporality which further harm the old people's mind and body rather than meeting the old people's spiritual needs and solving their emotional problems. 


\section{Cause analysis on geriatric social work function absence in civilian-run retirement organizations}

3.1 Nursing workers are lacked, and investors and managers temporarily take nursing effects as the sole beneficial pursuit

Under the situation that professional nursing workers and service staffs are lacked, rural women who work in towns and some off workers become the main source of nursing workers in civilian-run retirement organizations. The educational level of this group is low, so the service they offer to the old people is confined to physical nursing. Even though there is no any cultural and technical requirement for the employees, the amount of nursing workers is far less than the needs of retirement organizations because nursing workers' welfare treatment isn't good. In order to save cost, civilian-run retirement organizations will give nursing workers too heavy workload. For example, a nursing worker should nurse 4-6 old people at the same time. Such heavy workload makes nursing workers unable to communicate with the old people and pay attention to their emotional expression. On the other hand, nursing workers may have negative emotion and vent to the old people. Such kind of personnel status can't realize mental nursing service and meet the old people's spiritual needs at all.

3.2 Investors and managers take cost saving as starting point and cut down the cost of hiring professional social workers

In order to save cost, civilian-run retirement organizations generally don't hire professional social workers. The solution to problems when they notice the mental nursing service needs of old people in organizations is to invite volunteers who mainly come from enterprises, public institutions, and colleges. Temporary volunteers need to accomplish their tasks or projects in retirement organizations, so they are "public-minded" and "free" during the temporary service period. They don't need any cost, so both can take what they need. However, the eventual sufferer is the old people in organizations.

3.3 Managers" "illiterate" understanding of social working knowledge and idea causes the function absence of geriatric social work

3.3.1 Family echelon management makes workers lack of social work awareness

At present, the management and administration of majority civilian-run retirement organizations in Tianjing City are family business mode. Investors mainly concern that "people on their own side are trustworthy", so the management positions are occupied by their relatives. These managers seldom have professional or related background let alone possessing professional awareness of social work. When universities and colleges recommend students with educational background of social work major to them, they can hardly let "outsiders" who are not their relatives occupy a management position.

3.3.2 Professional managers mainly have medical nursing background but no social work educational background

Most civilian-run retirement organizations will hire one or two principals for "nursing department" out of nursing needs. These managers generally come from hospitals. They are the retired nurses and head nurses who have rich medical nursing experience, and are extremely good at managing nursing workers and training nursing workers' nursing technology. They have medical background but lack social work knowledge and idea because social work education starts late and professional education hasn't been popularized. They don't know and don't pay attention to social work's effects and significance on retirement organizations.

3.3.3 Family members' neglecting the old people's mental nursing needs makes civilian-run retirement organizations pay no attention to mental service

In general, the reason why the old people enter retirement organizations is that their self-care ability is so poor that they need caregivers, but their children don't have time and energy. As for the old people living in retirement organizations, what their family members care most are the old people's nursing situation. For example, how is the food there? How is the living condition there? Is the living room clean? Is the old people's body clean? Are they safe? In a word, they care that the 
old people are "alive” in retirement organizations and seldom care their "living” there.

\section{Acknowledgments}

This paper is the staged achievement of a funding project of Tianjing philosophy and social science research design named "The loneness status of old people in Tianjing retirement organizations and its empirical researches on its social work intervention”. (Project number: TJSR12-029)

\section{References}

1. Kathleen McInnis-Dittrich. Geriatric Social Work: physiological, physiological and social evaluation and intervention [M]. The 2nd edition. Translated by Sui Yujie. Beijing: China Renmin University Press. 2008

2. Tong Limin. Geriatric Social Work[M]. Shanghai: Press of East China University of Science and Technology. 2006 